\title{
NSAIDS (NON- STEROIDAL ANTI- INFLAMMATORY DRUGS)- THEIR EFFECTS AND SIDE EFFECTS IN ORTHODONTIC THERAPY - A REVIEW
}

\author{
Isha Gargya $^{1}$, Baljeet Singh ${ }^{2}$, Sanjay Talnia ${ }^{3}$ \\ ${ }^{1}$ Senior Lecturer, Department of Orthodontics and Dentofacial Orthopaedics,Bhojia Dental College and Hospital,Himachal Pradesh, India \\ ${ }^{2}$ Professor and Head, Department of Periodontics, Bhojia Dental College and Hospital,Himachal Pradesh, India \\ ${ }^{3}$ Postgraduate student, Department of Oral Surgery, Maharishi Markandeshwar College of Dental Sciences and Research, Haryana, India
}

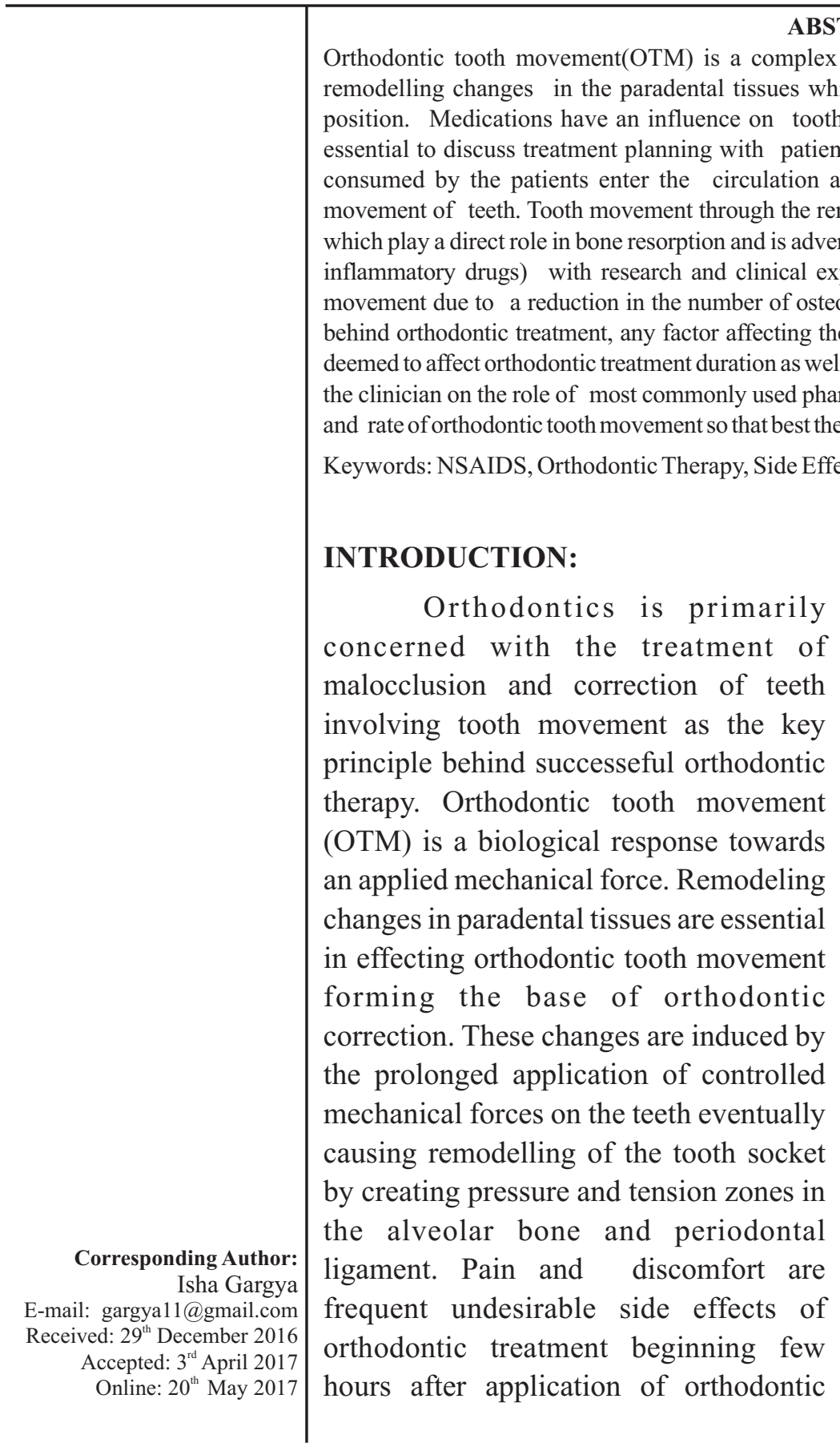

\section{ABSTRACT} the biologic response towards applied mechanical force is the clinician on and rate of orthodontic tooth movement so that best therapeutic strategy can be formulated for an individual.

Keywords: NSAIDS, Orthodontic Therapy, Side Effect

\section{INTRODUCTION:}

concerned with the treatment of malocclusion and correction of teeth involving tooth movement as the key principle behind successeful orthodontic therapy. Orthodontic tooth movement (OTM) is a biological response towards an applied mechanical force. Remodeling changes in paradental tissues are essential in effecting orthodontic tooth movement forming the base of orthodontic correction. These changes are induced by rolled ntually causing remodelling of the tooth socket by creating pressure and tension zones in the alveolar bone and periodontal ligament. Pain and discomfort are frequent undesirable side effects of orthodontic treatment beginning few 8 force and lasting for approximately 5 days. ${ }^{1}$ The control of pain during orthodontic tooth movement is therefore of interest to both patient and the orthodontist. Molecules present in drugs \& nutrients consumed regularly by patients reach mechanically stressed paradental tissues through the circulation and may be inhibitory, additive or synergistic. Drugs that alter or interfere with the inflammatory processes have an effect on the movement of teeth.

The drugs used in orthodontics can be broadly classified into two major groups, promoter drugs and suppressor agents. Promoter drugs are agents that act with secondary and primary inflammatory mediators and enhance tooth movement, e.g; Prostaglandins, Leukotrienes, Cytokines, Vitamin D, Osteocalcin, and Corticosteroids. Suppressor drugs are those which reduce 
bone resorption examples are; Nonsteroidal antiinflammatory agents and bisphosphonates. Periodontal remodeling is regulated in part by prostaglandins and adversely affected by the use of NSAIDs (Non Steriodal anti-inflammatory drugs). ${ }^{2}$ The term NonSteroidal anti- inflammatory drugs was coined since the use of Sodium salicylate in 1875 for the relief of fever and pain. NSAIDs are widely used because of their beneficial effects such as antipyresis, analgesic, anti- inflammatory and anti-platelet aggregatory effects. Aspirin is the drug of choice for Rheumatoid arthritis, osteoarthritis and post Myocardial infarction subjects since it has anti platelet aggregatory effects. Similarly, nimesulide has been used for short lasting painful inflammatory conditions such as post-dental surgery, sports injuries and sinusitis.

Prostaglandins (e.g PGE) are a group of chemical messengers belonging to the family of hormones called eicosanoids. They are lipid mediators derived from archidonic acid and play important role in inflammation and pain. ${ }^{3,4}$ Several studies have proposed the effect of short and long term administration of NSAIDS on orthodontic tooth movement. $^{5}$

The aim of this review article is to have proper knowledge of the mechanisms of action and effects of the some commonly used pharmaceutical products e.g NSAIDs so that the clinician selects best therapeutic strategy for an individual.

\section{NON STEROIDAL ANTI- INFLAMMATORY DRUGS:}

Nonsteroidal anti-inflammatory drugs (NSAIDs) are many a times used in the management of pain or discomfort ${ }^{6}$ following mechanical force application to the teeth during orthodontic treatment. NSAIDs act by inhibiting the prostaglandin (PG) synthesis since they are responsible for pain (hyperalgesia).Although chemically disparate, they produce therapeutic effects by the common ability to inhibit the activity of Cyclooxygenase enzymes (COX1, COX-2) ${ }^{7}$ (Figure 1). They include derivatives of salicylic acid (e.g., aspirin, diflusinal), propionic acid (e.g., naproxen, ibuprofen, flurbiprofen, ketoprofen), acetic acid (e.g.indomethacin, etodolac, diclofenac, ketorolac), enolic acid (e.g., piroxicam, phenylbutazone), fenamic acid (e.g., mefenamic acid, meclofenamic acid), alkanones(nabumetone), and diaryl heterocyclic compounds (e.g., celecoxib, valdecoxib, rofecoxib, etoricoxib). Aspirin irreversibly inhibits COX activity, which reduces the number of prostaglandins, thromboxanes $\left(\mathrm{TXA}_{2}\right)$, and prostacyclins $\left(\mathrm{PGI}_{2}\right)$ which play important role in normal physiologic processes, ${ }^{8}$ and induce altered vascular \& extracellular matrix remodeling causing decreased range of tooth movement through a reduction in the number of osteoclasts. $^{9,10}$

Hence, the use of over-the-counter nonsteroidal anti-inflammatory drugs during tooth movement may result in aberrant remodeling of periodontal vasculature and other structures, ultimately affecting orthodontic treatment efficacy.

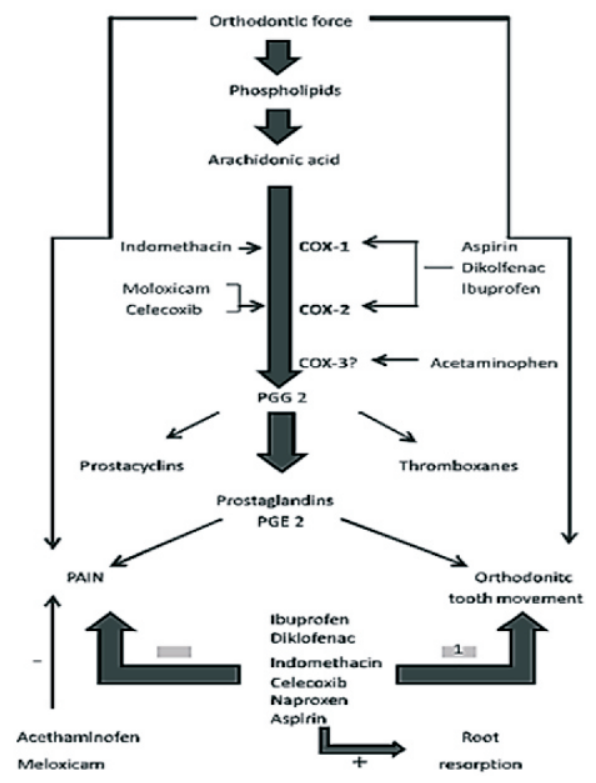

Figure 1. Mechanism of action of NSAIDs in tooth movement resulting from orthodontic forces.

\section{ASPIRIN:}

Aspirin modifies enzymes COX-1 and COX-2, irreversibly inhibiting their activity as discussed earlier. Salicylates i.e. aspirin affect the composition, biosynthesis, or metabolism of connective tissue mucopolysaccharides in the ground substance that provides barriers to the spread of infection and inflammation (Figure 2). 


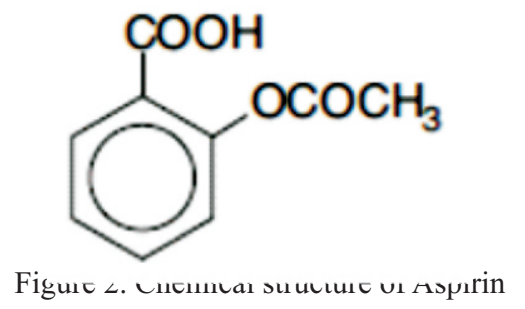

Aspirin is rapidly deacetylated in the gutwall, liver, plasma and other tissues and releases salicylic acid which is its major circulating and active form. It is $80 \%$ bound to plasma proteins and its volume of distribution $0.17 \mathrm{~L} / \mathrm{kg}$. It slowly enters brain but freely crosses placenta. Sari et $\mathrm{al}^{11}$ in their study found that PGE2 levels of gingival crevicular fluid decreased by $12.4 \mathrm{pg} / \mu \mathrm{L}$ in the aspirin group which indicated that aspirin inhibits prostaglandin (PG) synthesis during the first 24 hours. The PGE2 levels peaked at 24 hours and decreased nearly to baseline levels by 168 hours. Aspirin significantly reduced the numbers of resorption lacunae and osteoclasts in the pressure areas of orthodontic tooth movement.

\section{PARACETAMOL}

Paracetamol ( $N$-acetyl-p-aminophenol) also known as Acetaminophen was introduced in 1887 and is an analgesic, antipyretic. It is the active metabolite of phenacetin and is in use since $1950^{12}$ (Figure 3). It is available without a prescription and is used as a common household analgesic. It is part of a class of drugs known as "aniline analgesics. ${ }^{13}$ Since it is inactive as an anti-inflammatory agent in peripheral tissues, it does not have any adverse effect on PG biosynthesis and subsequent bone resorption associated with orthodontic tooth movement, unlike the NSAIDs. It is a weak COX-1 and COX-2 inhibitor. Paracetamol acts on a third isoform, COX-3, which is expressed only in the brain and the spinal cord. Studies have suggested that paracetamol does not affect orthodontic tooth movement, so it's safe to use as a choice of pain management during orthodontic treatment. Acetaminophen raises the threshold to painful stimuli, thus exerting an analgesic effect against pain due to a variety of etiologies.

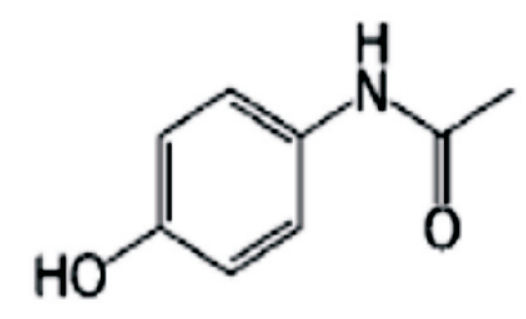

Figure 3. Chemical structure of Acetaminophen

A study by Roche JJ et al ${ }^{14}$ in 1997 reported that acetaminophen showed no effect on tooth movement when tested on rabbits. This drug is also available in fixed-dose combinations containing narcotic and nonnarcotic analgesics, barbiturates, caffeine in the form of vascular headache remedies, sleep aids, toothache remedies, decongestants, expectorants, cold and flu preparations, and sore throat treatments. Acetaminophen is a potent alternative to aspirin as an analgesic-antipyretic agent but its anti-inflammatory effects are weaker. Acetaminophen is well tolerated and has a low incidence of gastrointestinal side effects. The central analgesic action of paracetamol is like aspirin, i.e. it raises pain threshold with a weak peripheral anti-inflammatory action. Its properties are particularly useful for patients in whom aspirin is contraindicated (e.g. peptic ulcer, aspirin hypersensitivity, children with a febrile illness). Bartzela et $\mathrm{al}^{15}$ stated that the effect of paracetamol on orthodontic tooth movement in rabbits studied with the administration of $500 \mathrm{mg} / \mathrm{kg}$ per day had no effect on the rate of mesial molar movement. Since paracetamol does not affect the rate of tooth movement, it should be the drug of choice for the relief of orthodontic pain.

\section{ACETIC ACID DERIVATIVES (DICLOFENAC)}

Diclofenac is among the most extensively used non steroidalanti inflammatory drug employed in rheumatoid and osteoarthritis, spondylitis, toothache, dysmenorrhea, post-traumatic and postoperative inflammatory conditions and affords quick relief of pain and wound edema (Figure 4). It is aphenylacetic acid derivative and inhibits Prostaglandin synthesis (from archidonic acid) through inhibition of COX-1 and COX-2 enzymes and is particularly COX-2 
selective. It is marketed as sodium and potassium salts for oral administration.

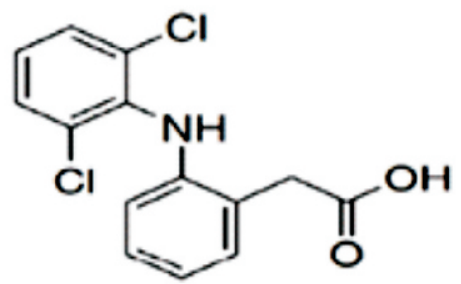

Figure 4. Chemical structure of Diclofenac

It has analgesic, antipyretic, and anti-inflammatory properties and its potency is greater than that of indomethacin, naproxen and several other NSAIDs. The usual daily divided oral dosage is $100-200 \mathrm{mg}$. Carlos et al in their study observed that 2 local injections of potassium diclofenac $(10 \mathrm{mg} / \mathrm{kg})$ totally eliminated $1^{\text {st }}$ molar movement in rats. ${ }^{16}$ Therefore it was concluded that when given in several divided doses, tooth movement is greatly inhibited or totally abolished by this drug.

\section{PROPIONIC ACID DERIVATIVES (IBUPROFEN)}

Discomfort and pain after initial separator or arch wire placement are common experiences among orthodontic patients. Ibuprofen (400mg) has been found equally or more efficacious than a combination of aspirin $(650 \mathrm{mg})+$ codeine $(60 \mathrm{mg})$ in relieving pain associated with dental surgery (Figure 5).

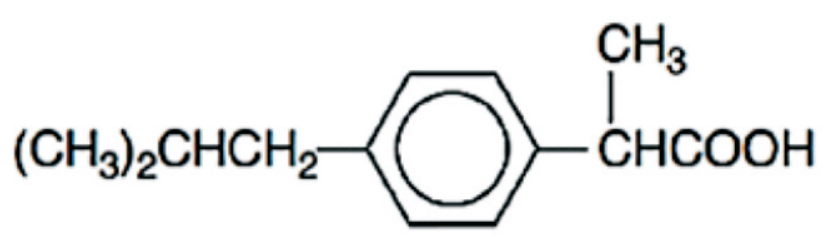

Figure 5. Chemical structure of Ibuprofen

Ibuprofen was introduced in1969 as an alternative to aspirin due to greater tolerance. It is a non-selective cyclooxygenase inhibitor. Ibuprofen is a propionic acid derivative and is well absorbed orally and is highly bound to plasma proteins (90-99\%). The mechanism for its anti-inflammatory effect is the blockage of prostaglandin synthesis in peripheral tissues. Kehoe et $\mathrm{al}^{17}$ found that ibuprofen significantly inhibits the production of prostaglandin $\mathrm{E}$ in the periodontal ligament and therefore decreases the rate of tooth movement. Bartzela et $\mathrm{al}^{15}$ also in their systematic literature review reported that after ibuprofen administration of $30 \mathrm{mg} / \mathrm{kg}$ twice a day in rats, the rate of orthodontic tooth movement decreases significantly.

\section{NIMESULIDE}

It is a weak inhibitor of prostaglandin synthesis and is Cyclooxygenase- 2 selective. Its antiinflammatory action is exerted by reducing the generation of superoxide by neutrophils, inhibiting platelet activating factor (PAF) synthesis. It is used after dental surgeries for relieving post-operative pain, sports injuries and dysmenorrhea. Its adverse effects are mainly gastrointestinal while its use has been banned in children in countries like Portugal and Israel. A histological study on guinea pigs revealed that nimesulide decreased the rate of bone resorption and appearance of osteoclasts and therefore, reduced the amount of tooth movement ${ }^{18}$.It is particularly useful in patients with asthma or with bronchospasm who are intolerant to aspirin. It is commercially available as $100 \mathrm{mg}$ tablets.

\section{CELECOXIB}

It is highly effective Cyclooxygenase enzyme2 inhibitor. It exerts anti-inflammatory, analgesic and antipyretic actions with low ulcerogenic potential. It tolerance was found to be better as compared to other NSAIDs. In relation to its effects during orthodontic treatment, it was found to have no effect on rate of tooth movement. ${ }^{19}$ It is useful in osteoarthritis and rheumatoid arthritis with a dose of $100 \mathrm{mg}$ twice a day. Its side effects include abdominal pain and mild diarrhoea. It is commercially available as $100 \mathrm{mg}$ capsules.

\section{INDOMETHACIN}

This drug is a highly potent inhibitor of prostaglandin synthesis and suppresses neutrophil motility. Its analgesic effects are better as compared to phenylbutazone. It has high incidence of gastrointestinal and central nervous system side 
effects, therefore, its use has been contraindicated in machinery operators, drivers, psychiatric patients, epileptics, pregnant women and children. It is a potent inhibitor of prostaglandin synthesis. When administered to mongrel cats as shown by Chumbley $\mathrm{AB},{ }^{20}$ the rate of tooth movement was found to be decreased. Its dose is about $25-50 \mathrm{mg}$ twice a day and is commercially available as $25 \mathrm{mg}$ or $75 \mathrm{mg}$ sustained release capsules. It is useful in ankylosing spondylitis and psoriatic arthritis and is also the most commonly used drug for medical closure of patent ductusarteriosus (PDA).

\section{CONCLUSION}

This review of literature summarizes the effects of medications, such as anti-inflammatory and analgesics in orthodontic tooth movement. Considering the increasing number of drugs available in the market, orthodontists have to constantly update their knowledge about drugs esp. NSAIDS and their influence on the duration of orthodontic treatment. The use of self-ligating brackets should be emphasised allowing use of less forces due to reduced friction. The expected duration of treatment should be prolonged and orthodontic forces be reduced or used at intervals. As orthodontists are routinely using NSAIDs during treatment they must also have understanding of fundamentals of drug therapy. Since NSAIDs effectively reduce the pain caused by orthodontic treatment, they also affect the tooth movement by reducing the inflammatory or bone resorption process. Acetaminophen (paracetamol) has been suggested as a safe and effective analgesic of choice for relieving discomfort associated with orthodontic pain.. Thus it becomes imperative for the clinician to update his/her knowledge on the clinical efficacy of the new drugs as well as their beneficial and harmful effects on human tissues. Orthodontist should be aware of the patients medical history and also converse with patient about the dosage and potential adverse effects.Also it is advisable for the clinician to confirm with the family physician for fitness of the patients undergoing corrective orthodontics.

\section{REFERENCES}

1. Aronoff DM, Oates JA, Boutaud O. New insights into the mechanism of action of acetaminophen: its clinical pharmacologic characteristics reflect its inhibition of the two prostaglandin $\mathrm{H} 2$ synthases. Clin Pharmacol Ther. 2006;79:9-19.

2. Goodman and Gilman. The pharmacological basis of therapeutics. 12th Edition California: McGraw Hill:2011.

3. Consolaro A. Orthodontic treatment does not cause pulpal necrosis. Dental Press Endod. 2011;1:14-20.

4. Lee WC. Experimental study of the effect of prostaglandin administration on tooth movement - with particular emphasis on the relationship to the method of PGE1 administration. Am J Orthod Dentofacial Orthop 1990;98:231-241.

5. Davidovitch Z, Finkelson MD, Steigman S, Shanfeld JL, Montgomery P. Electric currents, bone remodeling and orthodontic tooth movement Am J Orthod Dentofac Orthop 1980;77(1):33-47

6. Fernandes LM, Ogaard B, Skoglund L. Pain and discomfort experienced after placement of a conventional or a superelastic NiTi aligning archwire. A randomized clinical trial. J Orofac Orthop 1998;59:331-339.

7. Mitchell JA, Warner TD. COX isoforms in the cardiovascular system: understanding the activities of non-steroidal antiinflammatory drugs. Nat Rev Drug Discov 2006;5:75-86.

8. Sari E., Olmez H., Gurton AU. Am J Orthod Dentofac Orthop. 125, 310 (2004).

9. Mohammed A.H., Tatakis D.N., Dziak R. Am J Orthod Dentofac Orthop. 1989; 95: 231.

10. Arias O., Marquez-Orozco M. Am J Orthod Dentofac Orthop. 2006; $1301: 364$.

11. Stephanos Kyrkanides, M. Kerry O'Banion, J. Daniel Subtelny. Nonsteroidal anti- inflammatory drugs in orthodontic tooth movement: Metalloproteinase activity and collagen synthesis by endothelial cells. Am J Orthod Dentofac Orthop 2000;118:203-9.

12 K.D. Tripathi. Essentials of medical pharmacology. 6th edition. New Delhi: Jaypee-Highlight Medical Publisher.

13. Bertolini A, Ferrari A, Ottani A, Guerzoni S, Tacchi R, Leone S. Paracetamol: new vistas of an old drug. CNS Drug Rev 2006;12:250-275.

14. Roche JJ, Cisneros GJ, Acs G. The effect of acetaminophenon tooth movement in rabbits. Angle Orthod 1997;67:231-236.

15. Theodosia Bartzela, Jens C. Türp, Edith Motschall. Medication effects on the rate of orthodontic tooth movement: 
A systematic literature review. Am J Orthod Dentofacial Orthop 2009;135:16-26.

16. Felix de Carlos, Juan Cobo, Belen Díaz-Esnal, Juan Arguelles, Manuel Vijande, Marina Costales. Orthodontic tooth movement after inhibition of cyclooxygenase-2. Am J Orthod Dentofac Orthop 2006; 129: 402-6.

17. Kohoe MJ, Cohn SM, Cowan A. The effect of Acetaminophen, Ibuprofen and misoprotosol on PGE2 synthesis and degree and rate of tooth movement. Angle Orthod 1996;66(6)339-49.

18. Effect of analgesic and anti inflammatory drugs on orthodontic tooth movement- A biochemical and histological study in guinea pigs. IOSR Journal of Dental and medical sciences, volume 9(6):53-56.

19. DeCarlos F, CoboJ, Perillan C. Orthodontic tooth movement after different COXIB therapies. Eur J Orthod 2007;29:596599.

20. The effect of Indomethacin (aspirin like drug) on the rate of orthodontic tooth movement. Am J Orthod Dentofac Orthop 1986;89(4):312-4.

21. Drugs influencing orthodontic tooth movement : an overall review. Kamatchi Diravidamani, Satesh Kumar Sivalingam, Vivek Aggarwal. J Pharma Bioallied Sci 2012;4:299-303. 